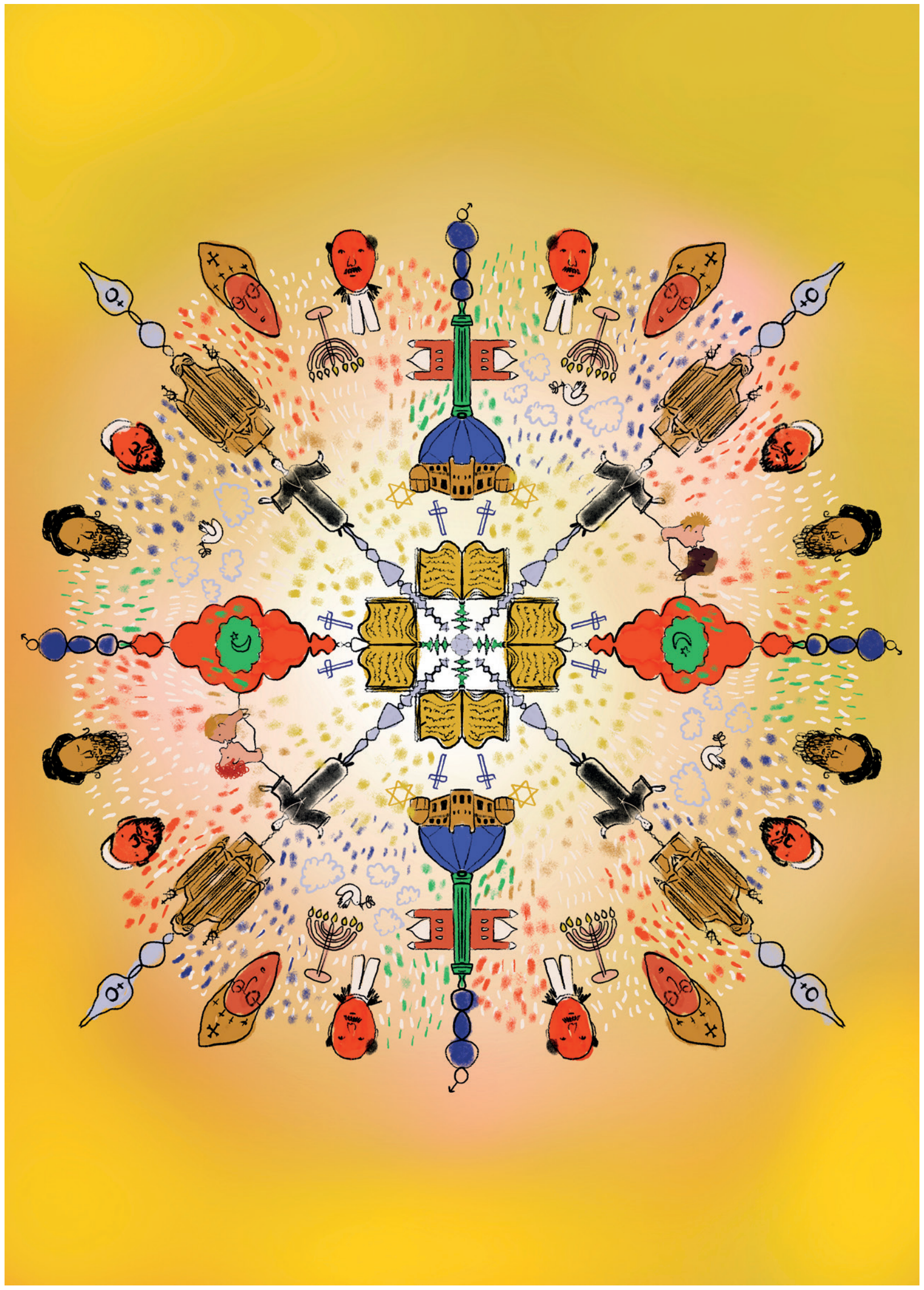




\title{
Religie in BMGN: heilig en profaan
}

\author{
JAN DE MAEYER
}

BMGN heeft inzake onderzoek en disseminatie van het thema religie een rol van betekenis gespeeld. Die rol nam BMGN veeleer impliciet op, zelden expliciet. Religie stond niet centraal in de redactionele missie, maar was inhoudelijk wel degelijk aanwezig en bij momenten ook heel zichtbaar. Het tijdschrift verbond niet alleen historici, het verbond ook onderzoek van historici en van andere menswetenschappers uit Nederland en Vlaanderen rond het thema religie en stimuleerde op velerlei wijzen de verspreiding van methodologische vernieuwingen en innovatieve inzichten. Jammer genoeg heeft BMGN religie of religiegeschiedenis nooit expliciet geproblematiseerd. Naast een meer klassieke benadering van religie (de werking van de geïnstitutionaliseerde religies of kerken) lag de focus op de rol van religie in het politieke en sociaal-maatschappelijke leven, maar ook in culturele evoluties (identiteitsopbouw of identiteitsconstructies). BMGN dreef veeleer mee met de ontwikkelingen in de religiegeschiedenis, het was geen trendsetter. In deze vaststelling schuilt een uitdaging voor de volgende tien jaar. Bij een feestnummer hoort een wens: religie mag en kan, als inherent onderdeel van de cultuurgeschiedenis, een explicieter onderdeel worden van BMGN.

The BMGN has been of great significance in researching and disseminating religion as a theme. The journal tended to assume this role implicitly but rarely did so explicitly. Religion was not pivotal in the editorial mission but indeed present in substance and at times very visible as well. In addition to connecting historians, the journal brought together research by historians, and by extension other scholars of the humanities, from the Netherlands and Flanders in relation to the theme of religion, and encouraged dissemination of methodological innovations and innovative insights in many ways. Unfortunately, the BMGN has never explicitly addressed religion or the history of religion. Aside from a more conventional approach to religion (the effect of institutionalised religions or churches), the main focus was the role of religion in politics and society, as well as in cultural transitions (identity constructions). The BMGN tended to go along with developments in the history of religion and was not a trend setter. This observation embodies a 
challenge for the decade that lies ahead. A festive issue includes a wish: religion is permissible and acceptable, as an inherent part of cultural history, as a more explicit part of the BMGN.

Bij het thema 'religie in BMGN' kan een lofzang passen, een Te Deum Laudamus, maar ook een lamentatie. Ik wil het houden bij een psalmdicht, waarin zowel de sterke kanten als de knelpunten in de relatie tussen de vijftigjarige BMGN en het thema religie in een hemels perspectief worden geplaatst. Lof en kritiek, heilig en profaan, dat kan, zoals in het leven zelf, in deze reflecterende bijdrage hand in hand gaan. Zelfs als we vertrekken van de etymologisch foutieve, maar wijdverspreide interpretatie van 'religiare', namelijk 'verbinden', dan nog heeft BMGN inzake onderzoek en disseminatie van het thema religie een rol van betekenis gespeeld. Die rol nam BMGN veeleer impliciet op, zelden expliciet. Religie stond niet centraal in de redactionele missie, maar was inhoudelijk wel degelijk aanwezig en bij momenten ook heel zichtbaar. Het tijdschrift verbond niet alleen historici, het verbond ook onderzoek van historici en bij uitbreiding andere menswetenschappers uit Nederland en Vlaanderen rond het thema religie en stimuleerde op velerlei wijzen de verspreiding van methodologische vernieuwingen en innovatieve inzichten. Het verdient alle lof dat opeenvolgende redacties nieuwe thema's in het onderzoek over religie, weliswaar in een brede betekenis, introduceerden en debatten aanzwengelden (zie grafiek 1). De BMGN nam dus, in de lijn van de betekenisgeving door de Romeinse politicus en filosoof Cicero, de rol van 'relegere' op zich, 'herlezen, overdoen, het nauwgezet in acht nemen'.

\section{Groot lofgezang}

Het mag terecht gezegd, BMGN herlas inderdaad de geschiedenis van religie in Zuid en Noord. ${ }^{1}$ Bij de lancering in 1970 wist het tijdschrift zich complementair en comparatief in te passen in het heterogene landschap van kerkhistorische periodieken in Nederland en Vlaanderen. BMGN onderscheidde zich van meet af aan van bijvoorbeeld het AGKKN-Archief voor de geschiedenis van de katholieke kerk in Nederland (1959-1991), het DKNDocumentatieblad voor de Nederlandse Kerkgeschiedenis in de negentiende eeuw/na 1800 (1977-) en van Trajecta. Tijdschrift voor de geschiedenis van het katholiek leven in de Nederlanden/Religie, cultuur en samenleving in de Nederlanden (1992-). BMGN liet in de voorbije vijftig jaar immers meer en meer het accent op het intra-kerkelijke 
aspect van de geïnstitutionaliseerde religies (de kerkelijke structuren, de leer, de actoren en het kerkelijk leven) los en verlegde geleidelijk de aandacht naar de interactie tussen religie, cultuur en samenleving in de Nederlanden, en dat, zoals gezegd, in een brede betekenis. Met deze geografische en inhoudelijke focus onderscheidde BMGN zich ook van de Belgische en internationaal gereputeerde Revue d'histoire ecclésiastique (1901-).

De focus op de interactie tussen religie, cultuur en samenleving groeide en hield een hele generatie historici bezig. De redactie was enerzijds afhankelijk van evoluties aan de aanbodzijde, anderzijds moest ze zich in de jaren zeventig en tachtig proberen te onttrekken aan de grote aandacht aan Noord-Nederlandse zijde voor wat zich in het kielzog van de Opstand en in de Republiek der Zeven Verenigde Nederlanden aan protestantse zijde had voorgedaan. Allicht was het daarom dat het enige themanummer over religie de titel 'Godsdienst in Nederland' droeg?² Een meer comparatieve betrokkenheid en benadering van de religieuze geschiedenis in de zuidelijke Nederlanden was geen evidente opdracht en kwam maar geleidelijk tot stand (zie ook grafiek 3 en 7 in bredere zin).

\section{Recensies: een gouden richtsnoer}

Van bij de aanvang zette BMGN in op een sterke recensierubriek die actief de maat wist te nemen van evoluties in de historiografie. De opeenvolgende redacties slaagden erin daarvoor gereputeerde experten in te schakelen. Vele boekbesprekingen waren behoorlijk kritisch, ze vormden in de eerste decennia een soort van peer reviewing avant la lettre. De recensies verschenen bovendien relatief kort na de publicatiedatum van de betrokken studies: de redactie speelde dus kort op de bal. Het resultaat oogt dan ook indrukwekkend: ik telde 3.833 boekbesprekingen waarvan er 719 (of 18,75\%) handelden over het thema religie, cultuur en samenleving in de Nederlanden in de brede betekenis. ${ }^{3}$ Geografisch bestreek de recensierubriek sinds 1970 de Nederlanden met inbegrip van de zogenaamde Franse Nederlanden en in mindere mate de Noord-Duitse grensregio's.

Inhoudelijk geeft de recensierubriek een rijk gevarieerd, caleidoscopisch beeld van de interactie tussen religie, cultuur en samenleving in de Nederlanden. Ze vormt een heuse gegevensbank die het evoluerende historisch onderzoek weerspiegelt, zowel op landelijk en bovenlokaal als op lokaal vlak. Zowat alle denominaties - maar met uitzondering van de orthodoxie en de islam - en de meest uiteenlopende thema's passeerden in BMGN de revue: bijbels (al dan niet met een grote erfgoedwaarde), preken,

3 Gebaseerd op een exhaustieve telling van 19702000, 2005, 2010, 2016-2020. 
boeteboeken en obituaria, de materiële cultuur van het christendom en het jodendom, de bouwgeschiedenis van kerken en kloosters, orgels en orgelluiken, de ontwikkeling van kerkgezangen en kerkkoren, de economie van abdijen of seculiere kapittels, de religieuze armenzorg of diakonie, (psychiatrische) zorginstellingen van joodse tot gereformeerde origine, religieuze broederschappen, heiligenverering en relieken, bedevaarten of processies, charivari, bedel-, ridder- of militaire orden, prosopografische studies van gereformeerde predikanten, rooms-katholieke priesters en rabbijnen, biografieën van bisschoppen of predikanten, missionering in relatie tot economische en politieke kolonisatie (de koloniale trilogie) en dekolonisatie, devotionele literatuur en poëzie, kruisvaarderromans, spiritualiteit en mystiek, de relatie tussen religie, seksualiteit en gender, de omgang van de geïnstitutionaliseerde religies met homoseksualiteit en lesbianisme, misbruik van kinderen en jongeren, religie en migratie, vluchtelingenkerken (inclusief de gemeenschappen van Hugenoten) en schuilkerken. Ook het toenemend belang van de pers en media kreeg aandacht, met inbegrip van de kerkelijke censuur. En de horizon van BMGN reikte nog verder: niet alleen de Reformatie of de Contrareformatie kwamen aan bod, maar ook de irenische ecclesiologie, bevindelijk gereformeerden, remonstranten, verlichte reformanten, anabaptisten, neocalvinisten en hun moreel-pedagogische opvattingen, gereformeerde piëtisten, de ultramontanen of papisten en de relatie van het katholicisme met totalitaire ideologieën zoals het fascisme. De BMGN zette zijn lezers telkens weer op een gericht en gevalideerd spoor.

\section{Innovatief, stimulerend, kwaliteitsbewakend}

Meer nog dan via de caleidoscoop aan recensies, komen de verdiensten van BMGN naar voren via de impulsen die het tijdschrift gaf aan vernieuwingen in het religieonderzoek. Dat gebeurde door innovatieve artikelen te publiceren, maar ook themanummers en reviewartikelen, en - nog ingrijpender - door bijdragen in de discussierubriek. Historici werden daarin voor de spiegel geplaatst, er werden hen keuzes voorgehouden, ze werden methodologisch uitgedaagd en aangemaand om nieuwe perspectieven en interpretaties uit te proberen, maar bij dit alles stond de kwaliteit voorop.

De multifocale, cultuurhistorische behandeling van religie in de context van het thema 'identiteit van de Nederlandse natie' vormt een mooi voorbeeld hiervan. ${ }^{4} \mathrm{Al}$ is het jammer dat daarvoor ook niet richting België 
werd gekeken, of werd de uitbreiding naar met name Vlaanderen een te complexe of te moeilijke opdracht geacht? Binnen deze thematiek werden vragen gesteld zoals: was Nederland inderdaad een domineesland zoals wel eens werd betoogd? Wat was het potentieel van het onderzoeksconcept 'civil religion' om de vervlechtingen tussen religie en de Nederlandse identiteit vanaf de Republiek der Zeven Verenigde Nederlanden tot heden bloot te leggen?5 ${ }^{5}$ at concept riep ook de vraag op of en in welke mate de veelgeprezen tolerantie van de Nederlandse natie te maken had met haar religieuze diversiteit: het lappendeken van denominaties, inclusief de vele afscheidingen aan protestantse zijde, die haar kenmerkte? En welke plaats moet men dan toekennen aan de moeizame emancipatie van religieuze minderheden, zoals de positie van de katholieken in de Republiek en in het negentiende-eeuwse koninkrijk? ${ }^{6}$

5 Zie het aan de problematiek 'identiteit en identiteitsbesef' gewijde nummer Bijdragen en Mededelingen betreffende de Geschiedenis der Nederlanden 107:4 (1992) met daarin bijvoorbeeld de bijdragen van Gerrit Jan Schutte, 'Nederland, een calvinistische natie', 690-702. DOI: https:// doi.org/10.18352/bmgn-Ichr.3594; Peter Raedts, 'Katholieken op zoek naar een Nederlandse identiteit, 1814-1898', 713-725. DOI: https://doi. org/10.18352/bmgn-lchr.3596, of nog meer in Horst Lademacher, 'Modernisering en emancipatie. Enkele opmerkingen over de Nederlandse negentiende eeuw', Bijdragen en Mededelingen betreffende de Geschiedenis der Nederlanden 104:1 (1989) 1-16. DoI: https://doi. org/10.18352/bmgn-lchr.3029; interessant is met betrekking tot civil religion de bijdrage van André Wierdsma, 'Religie en politieke rituelen en symbolen in Nederland na 1813', Bijdragen en Mededelingen betreffende de Geschiedenis der Nederlanden 102:2 (1987) 177-194. DoI: https://doi. org/10.18352/bmgn-Ichr.2811.

6 Joris van Eijnatten, 'Van godsdienstvrijheid naar mensenrecht. Meningsvorming over censuur en persvrijheid in de Republiek, 1579-1795', Bijdragen en Mededelingen betreffende de Geschiedenis der Nederlanden 118:1 (2003) 1-21. DoI: https://doi. org/10.18352/bmgn-lchr.5777; zie onder meer de bijdrage van James Kennedy en Jan Zwemer, 'Religion in the Modern Netherlands and the Problems of Pluralism', Bijdragen en Mededelingen betreffende de Geschiedenis der Nederlanden/The Low Countries Historical Review 125:2/3 (2010) 237268. DOI: https://doi.org/10.18352/bmgn-lchr.7121; Hans de Valk, 'Nederlandse katholieken in een overgangstijdperk. Omslag en terugslag in de jaren 1780-1830', Bijdragen en Mededelingen betreffende de Geschiedenis der Nederlanden 112:4 (1997) 487-501. DOI: https://doi.org/10.18352/bmgn-lchr.4569; en bijvoorbeeld Theo Clemens, 'De terugdringing van de rooms-katholieken uit de verlicht-protestantse natie', Bijdragen en Mededelingen betreffende de Geschiedenis der Nederlanden 110:1 (1995) 27-39. DOI: https://doi.org/10.18352/bmgn-lchr.3943; ook Johan Bosmans, 'Het onbehaaglijke vaderland. De katholieke staatkunde en de Staat der Nederlanden in de negentiende en twintigste eeuw', Bijdragen en Mededelingen betreffende de Geschiedenis der Nederlanden 108:3 (1993) 417-430. DOI: https:// doi.org/10.18352/bmgn-lchr.3704; maar ook zeker Willem Frijhoff, 'Katholieke toekomstverwachting ten tijde van de Republiek. Structuur, en grondlijnen tot een interpretatie', Bijdragen en Mededelingen betreffende de Geschiedenis der Nederlanden 98:3 (1983) 430-459. DOI: https:// doi.org/10.18352/bmgn-lchr.2416; de vroegste bijdrage was van Hans Guggisberg, 'Veranderingen in de argumenten voor religieuze tolerantie en godsdienstvrijheid in de zestiende en zeventiende eeuw', Bijdragen en Mededelingen betreffende de Geschiedenis der Nederlanden $91: 2$ (1976) 177-195. DOI: https://doi.org/10.18352/bmgn-lchr.1932. 
Het valt in dit laatste verband op hoezeer BMGN ruimte bood om het onderzoek over de joodse gemeenschappen in Nederland voor het voetlicht te brengen: van de Sefardische tot Portugese joden, de joodse gemeenschappen in Friesland, Amsterdam en Den Haag, en de niet religieuze of liberale joden. ${ }^{7}$ Het lijkt er op dat de opeenvolgende redacties van de studie van het jodendom een punt van eer maakten. Ook de verscheidenheid aan invalshoeken valt op: de omvang van de joodse gemeenschap, joodse praktijken en cultuurbeleving, integratie, toegewezen of verworven ruimte en infrastructuur. BMGN ging gevoelige thema's niet uit de weg zoals het negatieve discours over joden in de protestantse of katholieke kerken. Maar ook hiervoor ontbrak een comparatieve benadering met België/Vlaanderen, was dit het geval omdat vooral aan Franstalige kant aandacht aan het jodendom werd besteed en minder in de Nederlandstalige literatuur? Het Belgisch-Vlaamse perspectief kreeg wel een plaats wanneer het over de Jodenvervolging ging in de jaren 1920 en 1930, en tijdens de bezetting van noord en zuid in de Tweede Wereldoorlog. ${ }^{8}$

Het is eigenlijk ook logisch dat BMGN een rol van betekenis speelde in het onderzoek naar verzuiling en ontzuiling, al lag het accent sterk op wat zich in Nederland had afgespeeld. Vanuit de benadering van religie als een cultureel-maatschappelijke factor ging de aandacht haast automatisch naar de subculturen die de verschillende denominaties tot hechte pijlers hadden gemaakt, subculturen die vervolgens afbrokkelden ten gevolge van het versnelde secularisatieproces dat de Nederlandse samenleving in de jaren 1970-1980 trof. ${ }^{9}$ Tot dan had de verstrengeling tussen de religieuze identiteit - gereformeerd, hervormd of rooms-katholiek - en

de Joden in Nederland. Een discussiebijdrage naar aanleiding van twee recente studies', Bijdragen en Mededelingen betreffende de Geschiedenis der Nederlanden 94:1 (1979) 75-83. DOI: https://doi. org/10.18352/bmgn-Ichr.2069; Jozeph Michman, 'De emancipatie van de Joden in Nederland', Bijdragen en Mededelingen betreffende de Geschiedenis der Nederlanden 96:1 (1981) 78-82. DOI: https://doi.org/10.18352/bmgn-Ichr.2212. wetenschappen, bezettingstijd en jodenvervolging. Een besprekingsartikel', Bijdragen en Mededelingen betreffende de Geschiedenis der Nederlanden 120:4 (2005) 562-580. DOI: https://doi.org/10.18352/bmgn-Ichr.626o. het voortouw: Hans Daalder, 'Politicologen,

sociologen, historici en de verzuiling', Bijdragen en Mededelingen betreffende de Geschiedenis der Nederlanden 100:1 (1985) 52-64. DOI: https://doi. org/10.18352/bmgn-Ichr.2538; Piet de Rooy, 'De verzuiling vergruisd, de columnologie in opmars', 100:1 (1985) 65-69. DoI: https://doi. org/10.18352/bmgn-Ichr.2539; en tot slot Siep Stuurman, 'Verzuiling, geschiedenis en politiek', 100:1 (1985) 70-77. DOI: https://doi.org/10.18352/ bmgn-Ichr.2540. Zie ook Piet de Rooy, 'Zes studies over verzuiling', Bijdragen en Mededelingen betreffende de Geschiedenis der Nederlanden 110:3 (1995) 380-392. DoI: https://doi.org/10.18352/ bmgn-Ichr.4059; Jan van Miert, 'Verdeeldheid en binding. Over lokale, verzuilde en nationale loyaliteiten', Bijdragen en Mededelingen betreffende de Geschiedenis der Nederlanden 107:4 (1992) 670689. DOI: https://doi.org/10.18352/bmgn-Ichr.3593. 
de sociaal-culturele visie ideologieën gevormd die zich geroepen voelden op een allesomvattende, bijna totalitaire wijze antwoorden te formuleren op alle vragen in de samenleving. ${ }^{10}$ Die ideologieën beheersten de diverse sferen van het individuele en collectieve leven, iets waar ze zich in de gespannen jaren 1920 en 1930, en opnieuw in de jaren 1950 en 1960 , ijverig mee inlieten. BMGN bleef het verzuilingsonderzoek systematisch onder de aandacht brengen, ook vanuit een vergelijkend perspectief. De levensbeschouwelijke verzuiling was immers geen Nederlands unicum, maar tekende evengoed België/Vlaanderen en Duitsland (cf. de Duitse 'Milieuforschung'), wat het fenomeen voor een tijdschrift als BMGN alleen maar boeiender maakte. ${ }^{11}$ De redactie besefte goed dat de breedte en diepgang van de levensbeschouwelijke segregatie het gevaar creëerde van clichématig denken. Ze aarzelde niet om artikelen te plaatsen die waarschuwden voor karikaturale benaderingen. ${ }^{12}$

Verzuiling en ontzuiling verschenen in BMGN als complexe gegevens. Ze werden beschouwd als een uitdaging om de impact van religie op de samenleving op een historisch-kritische wijze te ontrafelen. Vooral het breder vergelijkend (West-)Europees perspectief bood analytisch kansen om de complexiteit van zowel verzuiling als ontzuiling te ontrafelen, maar ook om intrinsieke paradoxen bloot te leggen. Binnen de hoge muren van de zuilen vonden immers ook debatten en vormen van sociale en mentale emancipatie plaats, bijvoorbeeld rond ethische kwesties als geboortebeperking, abortus, euthanasie en rechten van LGBTQ'ers. De verzuiling liet enerzijds een gecontroleerde of getemperde emancipatie toe, maar bewaakte anderzijds haar identiteit door de debatten te beheersen en de emancipatie binnen de perken te houden. Tot in de stille jaren 1950, waarna de open dijkbreuk van de jaren 1960 zich manifesteerde.

Intussen wist BMGN ook andere trends uit het internationale historisch onderzoek op te pikken en via artikelen of in de discussierubriek onder de aandacht te brengen. Een treffend voorbeeld betreft het onderzoek over emoties. Vanuit haar cultuurhistorische benadering begreep de redactie snel dat de studie van emotie en religieonderzoek elkaar raken. Ze wist hierrond een aantal artikelen aan te trekken die als richtinggevend kunnen

Kuypers gereformeerde wereld herdacht',

Bijdragen en Mededelingen betreffende de

Geschiedenis der Nederlanden 110:4 (1995) 515-547. DOI: https://doi.org/10.18352/bmgn-lchr.4118.

11

van de nationale

geschiedenis en de verzuiling', Bijdragen en

Mededelingen betreffende de Geschiedenis der 
worden beschouwd. ${ }^{13}$ Ook de combinatie van emotie, genderonderzoek en religiegeschiedenis opende perspectieven: zo werd het fenomeen van religieuze 'zieners' en gestigmatiseerden in een vernieuwende culturele context geplaatst.

Een wat vergelijkbare rol speelde BMGN inzake onderzoek naar de interactie tussen religie en kolonisatie. Het tijdschrift poneerde expliciet het grote belang van deze internationaal georiënteerde onderzoeksthema's. Bijdragen met uitdagende titels zoals 'God dekoloniseert niet' van Jos de Beus trokken natuurlijk de aandacht. ${ }^{14}$ De kolonisatie en dekolonisatie werden wel meer vanuit een Nederlands dan Belgisch of comparatief perspectief benaderd. Een gemiste kans, maar voor deze lacune moeten de Belgische historici wel in de eigen boezem kijken. ${ }^{15}$ Kan ook de vaststelling meespelen dat het koloniale verhaal in Nederland meer verweven was met haar identiteit van protestantse, handelvoerende natie? Maar wat dan met de Onafhankelijke Congostaat van koning Leopold II en het daaropvolgende Belgisch-Congo? Gaven beide het katholicisme geen vleugels en deden ze niet dromen van een christelijk Afrika? De motieven van de geïnstitutionaliseerde kerken om mee te gaan in het koloniale verhaal vertoonden alleszins accentverschillen. In Nederland draaide het meer om identiteit en de zendingsgedachte, in België om het katholieke reveil en de gedachte dat het christendom gelijk stond aan civilisatie wat participatie aan het koloniale avontuur ondanks wat aarzelend voorbehoud meer dan wettigde. In België kwam de dekolonisatie beduidend later op gang dan in Nederland, toch wat Nederlands-Indië betreft. De religieuze dekolonisatie van Congo ging gepaard met een paradigmaverschuiving onder de invloed van 'nieuwe theologie' van de jaren

The Dutch and their Emotions in Pre-Modern

Times', BMGN - Low Countries Historical Review 129:2 (2014), maar ook het themanummer 'Low Countries Histories of Masculinity', BMGN - Low Countries Historical Review 127:1 (2012) met daarin de bijdrage van Tine Van Osselaer, 'Sensitive but Sane: Male Visionaries and their Emotional Display in Interwar Belgium', 127-149. DOI: https://doi.org/10.18352/bmgn-Ichr.1567. op de Nederlandse geschiedschrijving over de neergang van Nederlands-Indië en Nederlands Suriname', Bijdragen en Mededelingen betreffende de Geschiedenis der Nederlanden 116:3 (2001) 307-324. DOI: https://doi.org/10.18352/bmgnIchr.5499; J. van Goor, 'De grenzen van de koloniale geschiedenis', Bijdragen en Mededelingen betreffende de Geschiedenis der Nederlanden 97:1 (1982) 80-85. DOI: https://doi.org/10.18352/bmgnIchr.2290.

Zie Idesbald Goddeeris en Sindani E. Kiangu, 'Congomania in Academia. Recent Historical Research on the Belgian Colonial Past', Bijdragen en Mededelingen betreffende de Geschiedenis der Nederlanden/The Low Countries Historical Review 126:4 (2011) 54-74. DOI: https://doi.org/10.18352/ bmgn-Ichr.7442. En ook de bijdrage van Agus Suwignyo, Alicia Schrikker en Susan Legêne in dit nummer, 'How Generations Matter: BMGN and the Problem of Writing Histories of Colonialism', BMGN - Low Countries Historical Review 136:2 (2021) 68-85. DOI: https://doi.org/10.51769/bmgnIchr.9942. 
1950 over lokale kerkvorming: pro inculturatie van het katholicisme en de opbouw van een onafhankelijke Congolese kerk.

\section{Een kleine lamentatie}

Elke medaille heeft een keerzijde. Ook religie in BMGN is een verhaal met twee zijden. Misschien is religie té lang benaderd vanuit een eenzijdig Nederlands perspectief, om er een ook Belgisch/Vlaams en vergelijkend verhaal van te maken. Misschien dreef het tijdschrift teveel mee op de aanbodzijde en heeft het te weinig initiërend gehandeld. En waarom werden religies en kerken niet wat explicieter aan de orde gesteld? Waarom kwam religie in het themanummer '1900' (BMGN 106:4, 1991) niet voor, terwijl talrijke cultuurhistorische studies en tentoonstellingen over het breukjaar 1900 precies de veranderende omgang van intellectuelen en kunstenaars met religie ter sprake brachten ${ }^{16}$ Waarom geen aandacht voor het fenomeen van bekeerlingen in intellectuele kringen en voor de religieuze dimensie in kunstenaarskolonies? Waarom geen bijdragen of discussieartikelen over de islam en de inculturatieproblematiek in de Nederlanden ${ }^{17}$, de positionering van moskeeën en moskeeverenigingen, de migrantenkerken, de populariteit van het boeddhisme en het hindoeïsme (al dan niet als resultante van de culturele globalisering) of de opmars in alle geïnstitutionaliseerde religies van een virtuele of digitale religieuze participatie (los van de coviD-19-pandemie). Is een thema als de evoluerende positie van religie in grootsteden als Rotterdam, Antwerpen of Brussel denkbaar? Waarom de toch wel erg povere aandacht voor de georganiseerde vrijzinnigheid en de vrijmetselarij die zich beide goed lenen tot vergelijkend historisch onderzoek? Noblesse oblige, luidt het gezegde: BMGN had ook meer kunnen doen met het genderperspectief inzake religie door meer aandacht te besteden aan de positie van vrouwen in de geïnstitutionaliseerde religies, en de vergelijking ter zake tussen de denominaties, en tussen Vlaanderen/België en Nederland.

Jammer genoeg heeft BMGN religie of religiegeschiedenis ook nooit expliciet geproblematiseerd. Het lijkt wel of het thema voor de opeenvolgende redacties veeleer een impliciet gegeven was. Naast een meer klassieke benadering van religie (de werking van de geïnstitutionaliseerde religies of kerken) lag de focus op de rol van religie in het politieke en sociaal-

2000); interbellum (Nijmegen 2008).
17 Het artikel van Thijl Sunier, 'Naar een nieuwe schoolstrijd?', Bijdragen en Mededelingen betreffende de Geschiedenis der Nederlanden in het al vermelde themanummer 'Godsdienst in Nederland' 119:4 (2004) is een zeldzame uitzondering. DOI: https:// doi.org/10.18352/bmgn-lchr.6139. 
maatschappelijke leven, maar ook in culturele evoluties (identiteitsopbouw of identiteitsconstructies). BMGN dreef veeleer mee met de ontwikkelingen in de religiegeschiedenis, het was geen trendsetter zoals bijvoorbeeld het Schweizerische Zeitschrift für Religions- und Kulturgeschichte dat zich in de laatste decennia manifesteert met de introductie van nieuwe thema's als bijvoorbeeld oorlog en devotie, religie in opvoedingspraktijken, de historische impact van het apocalyptisch denken en antichristelijke polemieken. Het richtte ook de focus op bijvoorbeeld religiebeleving tijdens migratiestromen richting Europa en de betekenis van religie in vluchtelingen- of migrantengroepen. De uitzondering vormt de levensbeschouwelijke verzuiling, waaraan BMGN vernieuwende aandacht besteedde in theoretisch-methodologische bijdragen en in artikelen over de weerslag van verzuiling op het maatschappelijk leven, voornamelijk in Nederland. Een tweede uitzondering was de aandacht voor religieuze minderheden, voornamelijk de joodse gemeenschappen, maar ook weer quasi exclusief in Nederland.

Beschouw gerust bovenstaand bilan als een uitdaging voor de volgende tien jaar. Voor mij kan en mag religie, als inherent onderdeel van de cultuurgeschiedenis, een explicieter onderdeel worden van BMGN. Goed voor een extra kaars op de verjaardagstaart van BMGN in 2030.

Jan De Maeyer is doctor in de geschiedenis, emeritus gewoon hoogleraar 'religie en samenleving na 1800' aan de KU Leuven en eredirecteur van KADOC - Onderzoeks en Documentatiecentrum Religie, Cultuur en Samenleving van de KU Leuven $\left(1976^{\circ}\right)$. Momenteel is hij rectoraal opdrachthouder archief- en erfgoedbeleid van de KU Leuven. Zijn onderzoek focust op de relatie tussen religie, cultuur en maatschappij en op de materiële uitingen van het christendom in de negentiende en twintigste eeuw. Illustratief hiervoor is het collectief volume dat in samenwerking met Peter Jan Margry (UvA) nog dit jaar verschijnt Material Change. The Impact of Reform and Modernity on Material Religion, 1780-1920 (Leuven: UPL). E-mail: jan.demaeyer@kuleuven.be. 


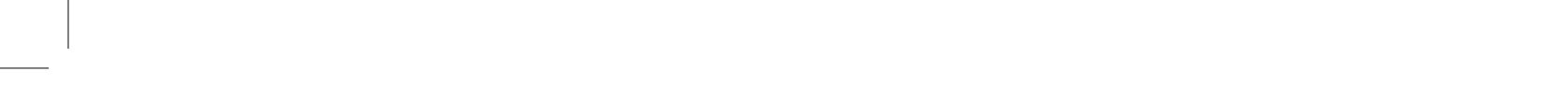

